\title{
Embrapa \\ Cerrados \\ GENETIC VARIABILITY OF MANGO (Mangifera indica L.) CULTIVARS USED IN THE EMBRAPA CERRADOS BREEDING PROGRAM USING RAPD MARKERS
}

Fábio Gelape Faleiro ${ }^{\circ}$, Alberto Carlos Q. Pinto', Maria Cristina R. Cordeiro', Victor Hugo V. Ramos ${ }^{1}$, Graciele Bellon ${ }^{2}$, Solange Rocha M. Andrade ${ }^{1}$ and Jefferson Fernando N. Pinto ${ }^{3}$

Embrapa Cerrados, Caixa Postal 08223, CEP 73310-970, Planaltina-DF:

${ }^{2}$ UPIS-Faculdades Integradas; ${ }^{3}$ Universidade Federal de Goiás

*e-mail: ffaleiro@cpac.embrapa.br

\begin{abstract}
[NERODLCETON
Embrapa Cerrados Research Center has been working on mango breeding program through intervarietal hybridization using cultivars from India, South Africa, Nigeria, Mexico, USA and Brazil since 1983. The objective of the breeding program is to develop mango hybrids with high productivity, high fruit quality, regular production, disease resistance, reduced height and adapted to the Savanna and Northeast Brazilian region conditions. For this, genetic material are evaluated in field and laboratory (Fig. 1).

An important step of the breeding program is the characterization of genetic resources, aiming at the genitor selections to be used on the hybridization. In general, this characterization is only based on agronomic and morphological characteristics (lyer and Dinesh, 1996). The DNA molecular markers are a new and powerful tool which make easier the characterization of genetic resources used at breeding program (Adato et al., 1995; Schnell et al., 1995). The genetic variability study of potential genitors for breeding programs is important to help in the selection of the parental groups to be used in the hybridization work and also to help the successive procedures of the breeding program.
\end{abstract}

\section{(0)BJECLTVI5}

The objective of this work was to use molecular markers in order to evaluate the genetic variability of 28 mango cultivars of the parental group used in the breeding program carried out at Embrapa Cerrados, aiming to add useful information to the program, such as genetic distances and genetic variability of these introduced cultivars from different countries and regions.
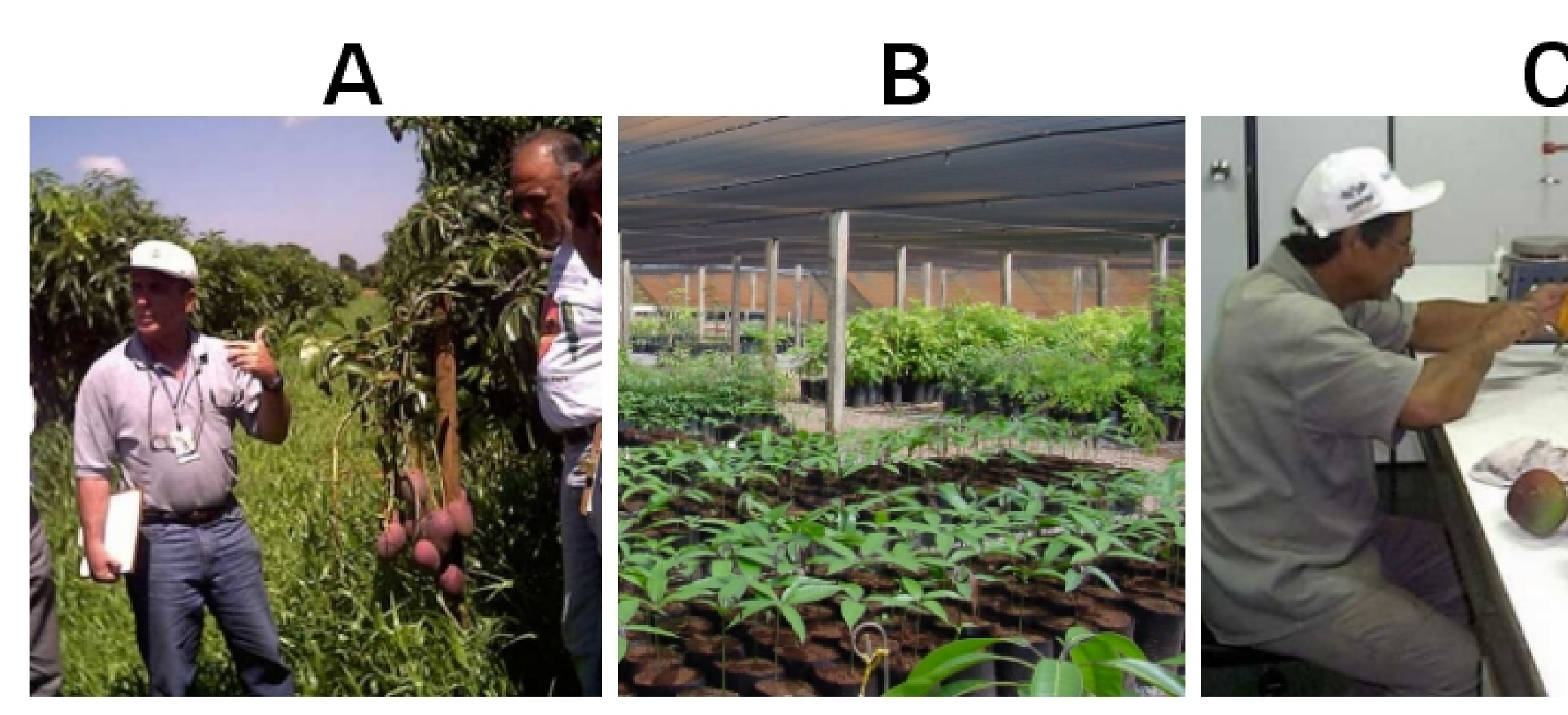

C

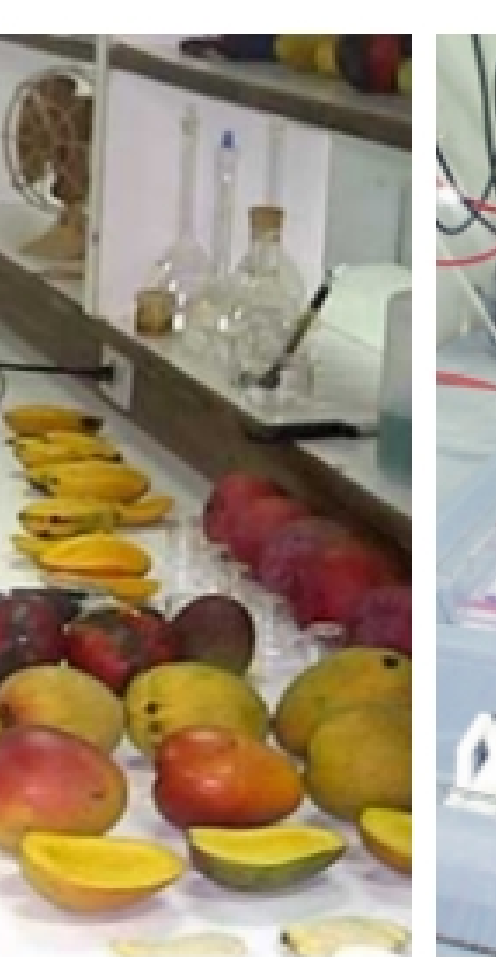

D

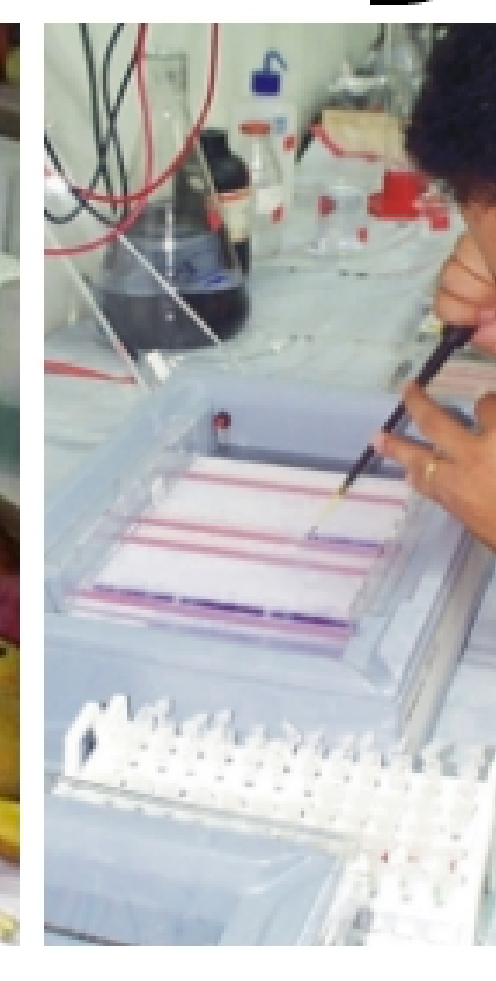

breeding program carried out at Embrapa Cerrados.

RESETLLTS

A total of 350 RAPD bands were generated by using 21 decamer primers (a mean of 16.7 bands per primer). The products of amplification of the DNA for the 28 mango cultivars obtained by the primer OPD-02 are shown in Fig 3. Among the 350 bands, $293(83.7 \%)$ were polymorphic and $57(16.3 \%)$ monomorphic

The genetic distances among the 28 cultivars ranged from 0.098 to 0.331 . The lowest genetic distances were detected between the cultivars Edward and Glenn (0.098), Tommy Atkins and Keitt (0.101), as well as between Apple and Malindi (0.112). The genetic similarity between Edward and Glenn can be explained because both are known as seedlings of Haden. Tommy Atkins and Keitt also have common genetic ascendance, probably, from Mulgoba variety. The Apple and Malindi cultivars have presented the same phenotypic characteristics at Embrapa Cerrados mango collection.

The graphic analysis, based on the genetic distances, shows that the Brazilian and Indian mango cultivars are very dispersed in the scattered plot (Fig 4), evidencing a high genetic variability among these cultivars. On the other side, there was a group tendency of the important cultivars from USA and South Africa (Fig 4). The group of USA cultivars also was observed by López-Valenzuela et al. (1997).

\section{MAEFERLALAND MEETLODS}

For the present study were analyzed 28 mango (Mangifera indica L.) cultivars that have been used in Embrapa Cerrados Breeding Program (Table 1). Leaf samples of each mango cultivar were collected in the Embrapa Cerrados mango collection (Fig. 2) and the genomic DNA was extracted from each sample, by using the method of CTAB, with some modifications (Faleiro et al., 2003). DNA samples, from each cultivar, were amplified using the RAPD (Random Amplified Polymorphic DNA) technique.

Amplific ation reactions were done in $13 \mathrm{uL}$ total volume, containing Tris- $\mathrm{HCl} 10 \mathrm{mM}(\mathrm{pH} 8,3), \mathrm{KCl}$ $50 \mathrm{mM}, \mathrm{MgCl} 23 \mathrm{mM}, 100 \mathrm{uM}$ from each of the desoxiribonucleotídes (dATP, dTTP, dGTP e dCTP), 0,4 uM of a primer (Operon Technologies Inc., Alameda, CA, EUA), one unit of the Taq polimerase enzyme and, approximatelly, $15 \mathrm{ng}$ of DNA. The decamer primers OPD-02, OPD-03, OPD-12, OPD13, OPD-15, OPD-19, OPE-01, OPE-06, OPE-11, OPF-02, OPF-03, OPF-05, OPF-07, OPF-08, OPF12, OPG-02, OPG-10, OPG-11, OPH-04, OPH-19 and OPH-20 were used to start the amplifications. The amplifications were performed in a termociclator programmed for 40 cycles, each one with the following sequence: 15 seconds at $94^{\circ} \mathrm{C}, 30$ seconds at $35^{\circ} \mathrm{C}$ and 90 seconds at $72{ }^{\circ} \mathrm{C}$. After the 40 cycles, there was a final extension phase, which lasts for 6 minutes at $72^{\circ} \mathrm{C}$, and finally, temperature was reduced to $4{ }^{\circ} \mathrm{C}$. After the amplification, each sample received the adition of 3 ul of a loading mixture containing bromophenol blue $(0,25 \%)$ and glicerol $(60 \%)$ in water. These samples were applied in agarose gel $(1,2 \%)$, stained with ethidium bromide, submerged in TBE (Tris-Borato $90 \mathrm{mM}$, EDTA $1 \mathrm{mM}$ ) buffer. Electrophoresis lasted about four hours at 90 volts, approximately. Following this electroforesis, the gels were photographed under ultraviolet light.

The obtained RAPD was transformed into a matrix of binary data, from which genetic distances based on the complement of the similarity coefficient of Nei and Li were calculated with the software Genes. The matrix of genetic distances was displayed in a biplot based on the multidimensional scaling, using the principal coordinates analysis method. The software SAS and Statistic were used for the analysis and plot construction.

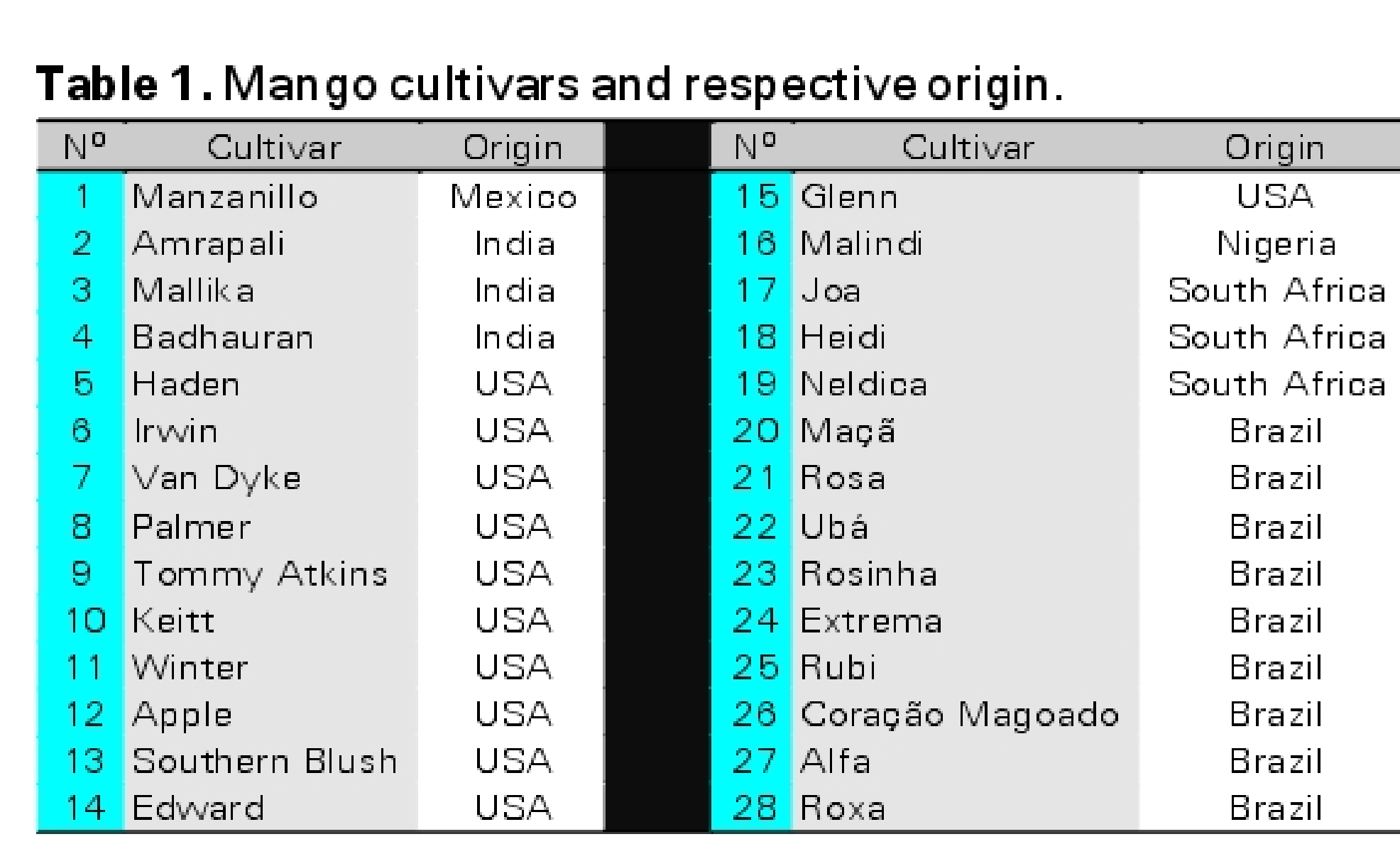

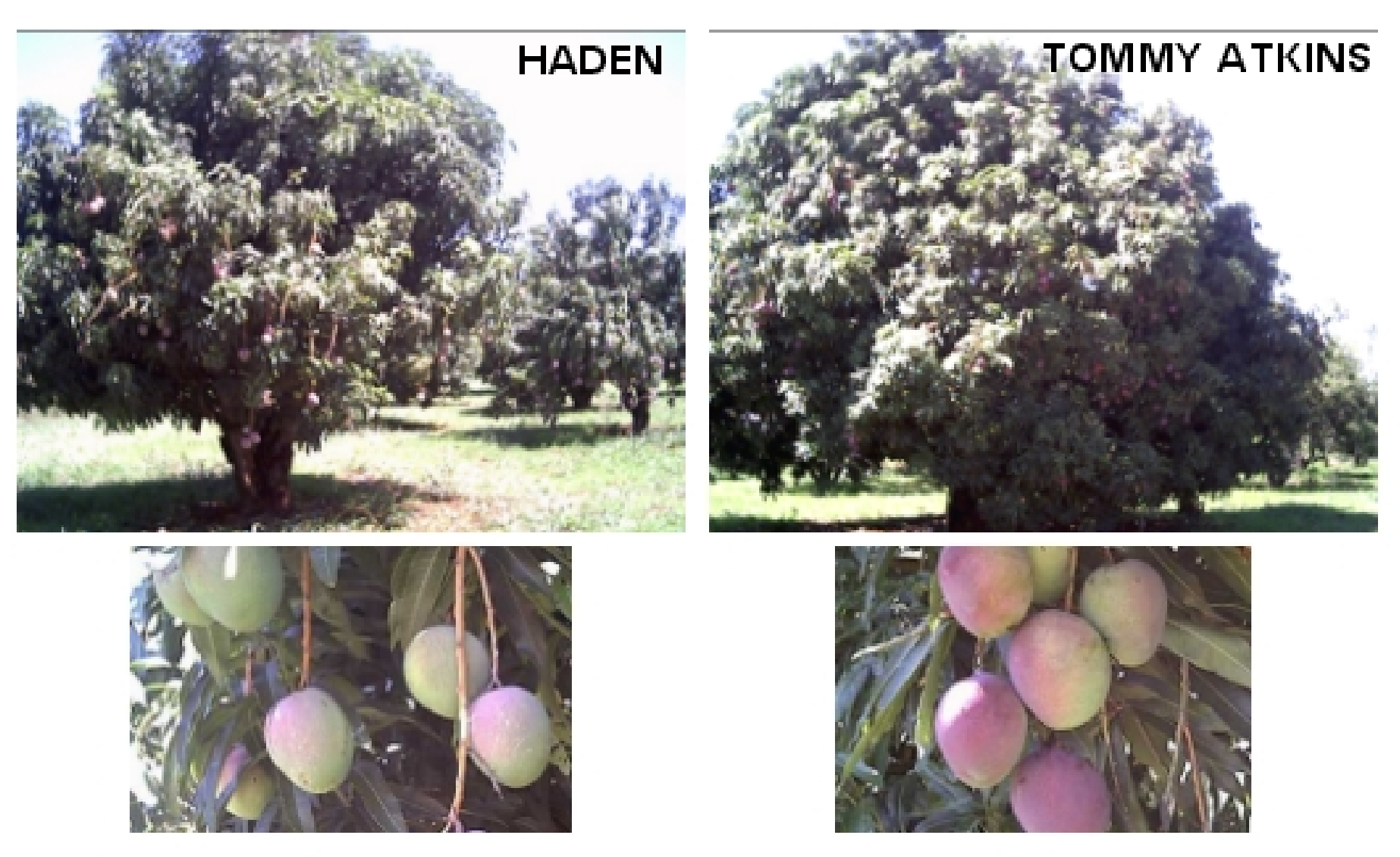

Figure 1. Embrap a Cerrados mango collection eviden cing the Haden and Smith cultivars. Ther
different accessions in the collection.
The cultivars Mallika, Tommy Atkins, Keitt, Alfa and Roxa used on the actual breeding program at Embrapa Cerrados are dispersed in the scattered plot (Fig 3), however, Mallika and Alfa are closed, probably because Alfa is originated from the cross between Mallika and Van Dyke cultivars. 'Tommy Atkins' and 'Keitt' are also closed in the scattered plot since both have Mulgoba in their ascendances. The selection of these genitors was made using agronomic desirable characteristics like dwarfness, high and regular productivity, commercial fruit quality and disease resistance (Pinto, 2000).

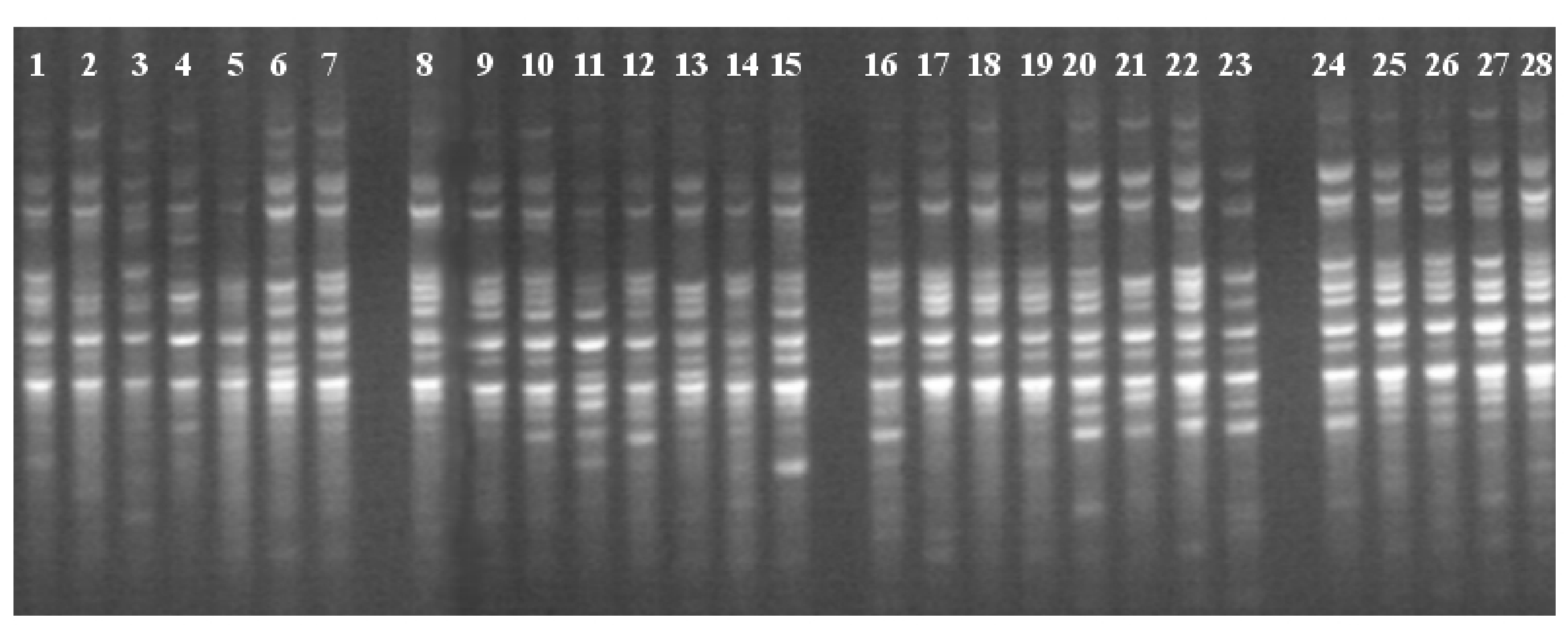

Figure 3. Amplification products of genomic DNA from 28 mango cultivars using the RAPD decamer primer OPD-02. The cultivar corresponding to each number is presented in the Table 1 .
The use of only agronomic characteristics can result in the drastic reduction of the cultivars genetic variability. The results of this work show that new genitors can be selected using the combination of genetic diversity analysis and agronomic characteristics.

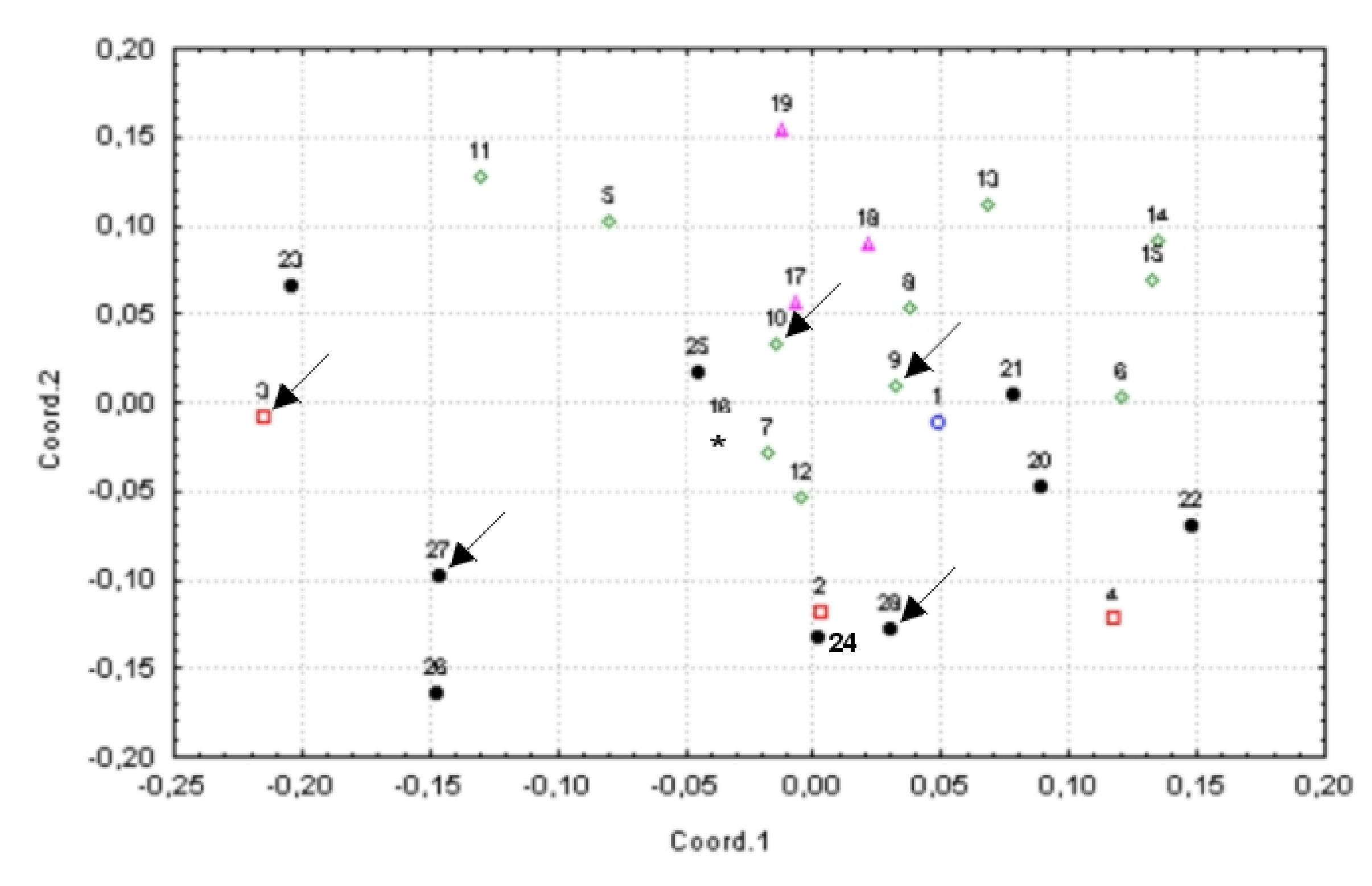

Figure 4. Dispersion analysis of 28 mango cultivars using the genetic distances among them calculated with 350 RAPD markers. The cultivars are

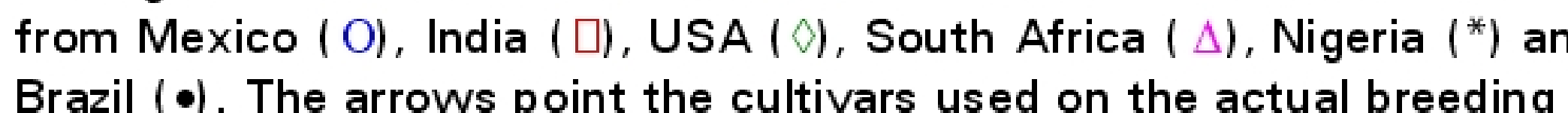
program realized in the Embrapa Cerrados. The cultivar corresponding program realized in the Embrapa Cerrados.
to each number is presented in the Table

\section{CONCL-CJSLONS}

The results of this work show the utility of the molecular markers to study the genetic relationships among mango cultivars, emphasize the importance of the cultivars used in the Embrapa Cerrados breeding program and provide useful information for future mango intervarietal hybridization breeding activities.

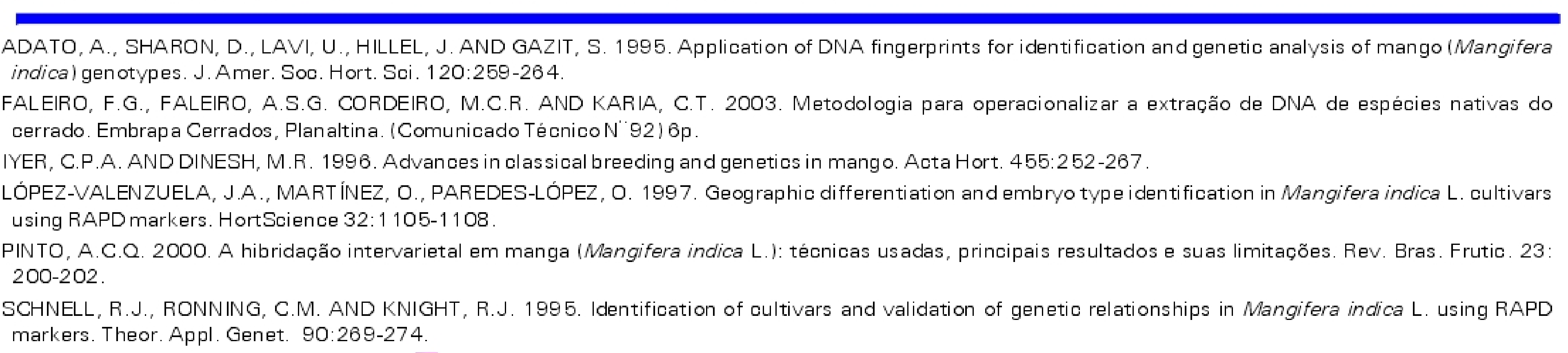

